\title{
Failure to Fire
}

National Cancer Institute

\section{Source}

National Cancer Institute. Failure to Fire. NCI Thesaurus. Code C63177.

Problem associated with failure of the device to discharge its load (e.g. surgical stapler failed to partially or completely deploy its staples). 